\title{
Is echographic evaluation of the Inferior Vena Cava reliable to predict an individual's position in the Frank-Starling curve?
}

\author{
Daniel Rodrigues Alves (Anaesthesiology resident) \\ Centro Hospitalar de Lisboa Ocidental, Lisbon, Portugal; Head of Department: Manuel Chedas
}

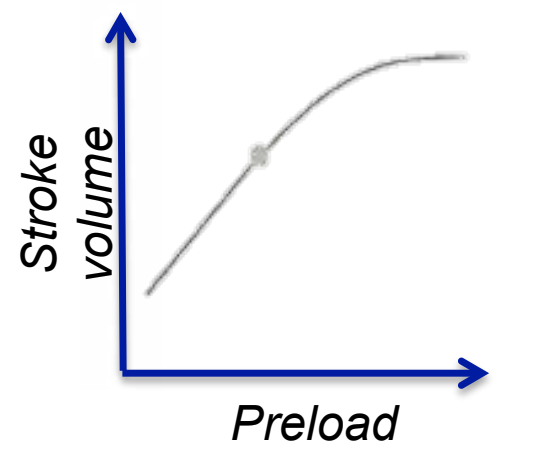

Figure 1 - FrankStarling curve.
Background and Goal of Study:

- A patient's position in the Frank-Starling curve and consequently his/her response to a fluid bolus are fundamental concepts in present-day goal-directed therapy ${ }^{1}$;

- However, for patients breathing spontaneously few indices are validated to answer this question, namely aortic VTI variation with the passive leg raise manoeuvre (PLR - gold standard) ${ }^{2}$ and, according to some authors, IVC evaluation ${ }^{3}$;

- However, and according to the European Association of Echocardiography, IVC assessment is seen as a method to ascertain CVP non-invasively ${ }^{4}$, which is an inadequate guide for fluid therapy ${ }^{5}$. Such leads us to reconsider the utility of IVC assessment in this context.

- The present study compares the gold standard with IVC indices in volunteers, so as to infer on its concordance.

\section{Materials \& Methods:}

- Observational, analytic study

- 31 ASA 1 and ASA 2 volunteers (each examined twice) -16F:15M - 26-67 years old • No cardiac comorbidities

- 62 echocardiograms performed (GE Vivid $7^{\circledR}$ ), using the PLR manoeuvre

- Statistical analysis with SPSS Statistics ${ }^{\circledR}$ version 21

\section{- Study variables}

- IVC indices (expiratory diameter and collapsibility index)

- $\Delta V T I_{A 0} P L R$

- $\Delta \mathrm{VTI}_{\mathrm{Ao}} \geq 10 \%=>$ fluid responsive

- $\Delta \mathrm{VTI}_{\mathrm{Ao}}<10 \%=>$ not fluid responsive
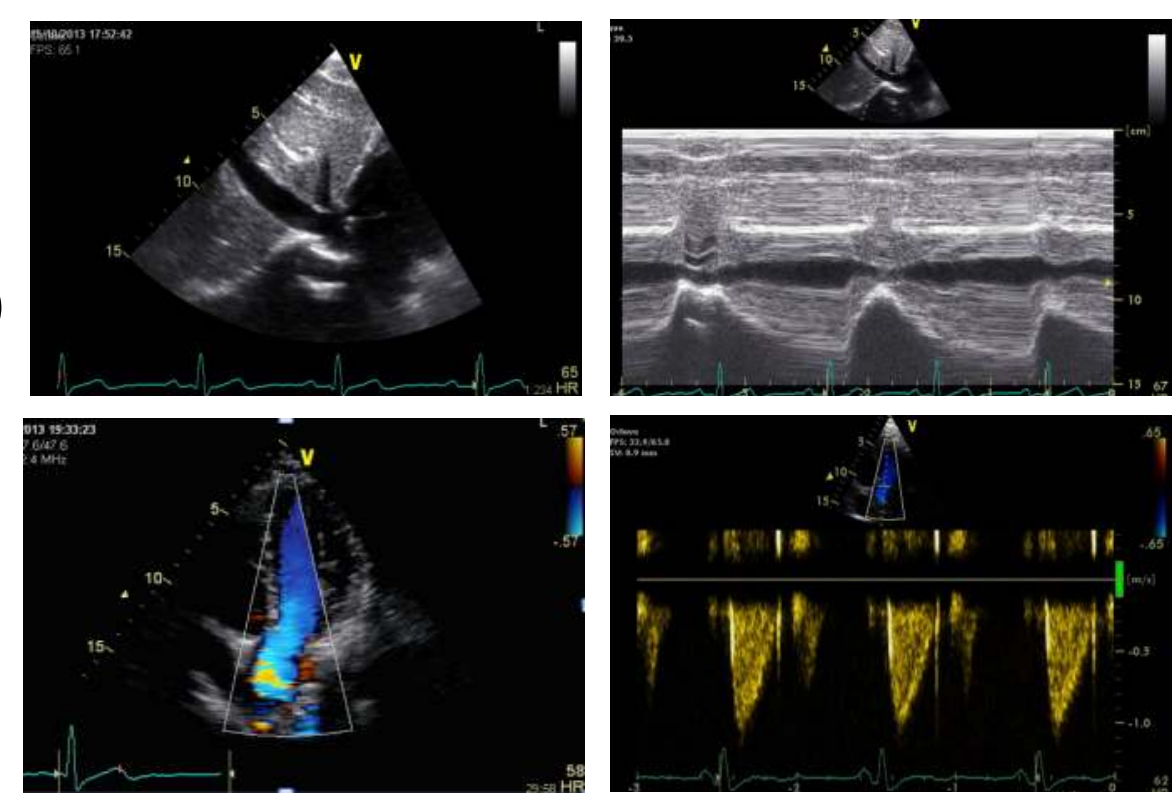

Results \& Discussion

- Is there a linear correlation between IVC indices and fluid responsiveness (signalled by $\Delta \mathrm{VTI}_{\mathrm{AO}} \mathrm{PLR}_{\text {)? }}$
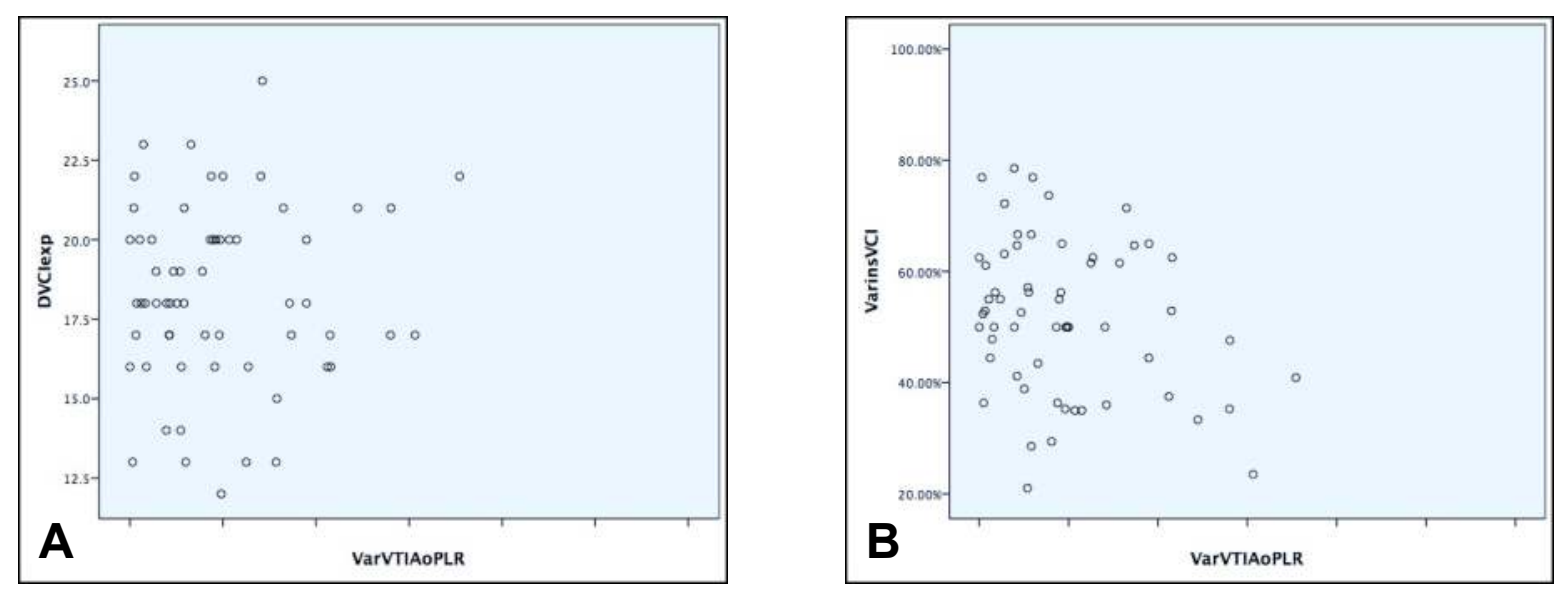

Figure 2 - Scatter plots: A- IVC expiratory diameter versus $\triangle \mathrm{VTI}_{\mathrm{Ao}_{0}} \mathrm{PLR}$ B- IVC collapsibility index versus $\Delta \mathrm{VTI}_{\mathrm{AO}_{0}} \mathrm{PLR}$.

\begin{tabular}{|c|c|c|c|}
\hline \multirow[b]{2}{*}{ Variable } & \multirow[b]{2}{*}{$\mathbf{N}$} & \multicolumn{2}{|c|}{ Correlation with $\triangle \mathrm{VTI} \mathrm{Ao}_{\mathrm{O}} \mathrm{PLR}$} \\
\hline & & $\begin{array}{c}\text { Pearson's correlation } \\
\text { coefficient }\end{array}$ & $\begin{array}{l}p \text {-value for Pearson's } \\
\text { correlation coefficient }\end{array}$ \\
\hline Dexp IVC & 62 & $-0,013$ & 0,920 \\
\hline$\Delta$ resp IVC & 62 & $-0,149$ & 0,248 \\
\hline
\end{tabular}

Table 1 - Pearson's correlation coefficient between IVC indices and $\triangle \mathrm{VTI}_{\mathrm{Ao}} \mathrm{PLR}$.

- Is there a relation (not necessarily linear) between IVC indices and fluid responsiveness?

\section{- Mann-Whitney test}

\begin{tabular}{|c|c|c|}
\hline Variable & $\mathbf{N}$ & p-value \\
\hline Dexp VCl & 62 & 0,906 \\
\hline resp VCl & 62 & 0,465 \\
\hline
\end{tabular}

Table 2 - Comparing the distribution of independent variables (IVC indices) between fluid responders and fluid non-responders.

\section{- Kruskall-Wallis test}

- After dividing individuals into classes according to EAE guidelines ${ }^{4}$ for estimating right atrial pressure using IVC, we compared fluid responsiveness within each class.

\section{Valor $p$} (teste de Kruskal-Wallis)

0,107

Table 3 - KW test: fluid responsiveness in different EAE classes.

\section{Conclusions:}

- IVC indices do not show a statistically significant relation with $\triangle \mathrm{VTI}_{\mathrm{Ao}} \mathrm{PLR}$, either in isolation or combined;

- Considering that $\triangle \mathrm{VTI} \mathrm{Ao}_{\mathrm{o}} \mathrm{PLR}$ is the gold-standard to infer fluid responsiveness under spontaneous ventilation, the present study discourages the use of IVC indices with that aim;

- Further, larger studies are advised, namely in critical patients and, ideally, with simultaneous evaluation of CVP before generalizing these results.

\section{Acknowledgements:}

The author would like to thank all the volunteers, all the members of the Echocardiography Laboratory of Santa Cruz Hospital in Lisbon (where the study took place) and the Anaesthesiology Department of Occidental Lisbon Hospital Centre.

\section{- Logistic regression model}

"Dependent" variable: $\Delta \mathrm{VTI}_{\mathrm{Ao}} \geq 10 \%$ versus $\Delta \mathrm{VTI}_{\mathrm{Ao}}<10 \%$ Independent variables: IVC expiratory diameter \& IVC collapsibility index

$$
\prod \quad \begin{aligned}
& \text { No linearity in logit } \\
& \text { (Box-Tidwell test) }
\end{aligned}
$$

Discretization of the sample according to EAE guidelines ${ }^{4}$

\begin{tabular}{|c|c|c|c|c|}
$\begin{array}{c}\text { Omnibus } \\
\text { test }(\boldsymbol{p})\end{array}$ & $\begin{array}{c}\text { Pseudo-R } \\
\text { (Nagelkerke) }\end{array}$ & $\begin{array}{c}\text { Hosmer \& } \\
\text { Lemeshow } \\
\text { test }\end{array}$ & $\begin{array}{c}\text { Wald } \\
\text { statistic }(\boldsymbol{p} \\
\text { for Dexp } \\
\text { VCI }\end{array}$ & $\begin{array}{c}\text { Wald } \\
\text { statistic }(\boldsymbol{p} \\
\text { for } \Delta \text { resp } \\
\text { VCI) }\end{array}$ \\
\hline 0,436 & 0,036 & 0,096 & 0,677 & 0,310 \\
\hline
\end{tabular}

Table 4 - Characteristics of the logistic regression model created. (Similar values were obtained for models with the independent variables considered in isolation.)
1- Ramos FJS, Azevedo LCP. Assessment of fluid responsiveness in patients under spontaneous breathing activity. Rev Bras Ter Intensiva. 2009;21:212-218

2- Pinsky MR. Goal-Directed Therapy: Optimizing fluid management in your patient. Initiatives in Safe Patient Care. 2010;1-12

3- Labovitz AJ, Noble VE, Bierig M, et al. Focused cardiac ultrasound in the emergent setting: a consensus statement of the ASE and ACEP. J Am Soc Echocardiogr. 2010;23:1225-1230

4- Lang RM, Bierig $M$, Devereux $R B$ et al. Recommendations for chamber quantification. Eur J Echocardiogr. 2006;7:79-108

5- Marik PE, Baram M, Vahid B. Does central venous pressure predict fluid responsiveness? A systematic review of the literature and the tale of seven mares. Chest 2008:134:172-178. 